Elena N. Mastenitsa,

Ph. D. in History, Associate Professor, Saint-Petersburg State Institute of Culture (Saint-Petersburg, Russia) elenamast@yandex.ru

\title{
MUSEUM INTER-GENERATIONAL COMMUNICATION IN PRESERVATION AND TRANSFERRING OF CULTURAL HERITAGE
}

\begin{abstract}
The paper gives a brief description of the key directions of work of a modern Russian museum with persons aged 60 years and above (retirement age); the segment of such visitors shows a stable dynamic growth in the total amount of museum public. Various role statuses of persons of the third age who act as participants of museum communication are named. The author analyses most popular forms of participation of retirement-aged persons in museum communication, such as: scientific museum exhibition, forms of cultural and educational activities, synthetic form of verbal and visual transferring, complex form of transferring of cultural heritage.

Key words: cultural heritage, a museum, cultural heritage in a museum, transferring cultural heritage in a тизеит культурного наследия в музее, a third-aged museum visitor, a museum visitor from late adulthood persons category, inter-generational museum communication, reintegration into society persons of retirement age by means of museum work.
\end{abstract}

УДК 130.2:316.73(4+5)

DOI 10.32340/2414-9101-2020-2-40-45

М. А. Носоченко, кандидат культурологии, доцент, Алтайский государственный институт культуры (Барнаул, Россия) caperucita.amarilla2016@gmail.com

\section{ВОСТОК - ЗАПАД: ПРОБЛЕМА ДИАЛОГА КУЛЬТУР}

Аннотация. Статья посвящена анализу сложной и длительной истории взаимоотношений Востока и Запада. Автор рассматривает некоторые аспекты развития восточной и западной интеллектуальных традиций в области логики, диалектики, гносеологии и теории сознания. Представлен сравнительный анализ принципов восточной (на примере Дхармакирти и Нагарджуны) и западной (на примере Аристотеля) логики, а также учений о душе и Эго-сознании. Цель работы показать, что подлинный диалог культур строится на поиске точек соприкосновения в интеллектуальной, художественной и религиозной сферах жизни общества без прямого заимствования чуждой системы ценностей. Такой диалог становится возможным при условии достижения культурами высокой степени зрелости, что проявляется, в частности, в осознании ими ограниченности собственных метафизических оснований. Полученные результаты свидетельствуют о преодолении Востоком изначально интровертной, а Западом - изначально экстарвертной - психической установки, что открывает возможности для конструктивного межкультурного диалога без риска утраты ими собственной идентичности.

Ключевые слова: философия, психология, теория культуры, логика, диалектика, феноменология, гносеология, теория сознания, Запад, Восток, диалог культур.

Теме диалога Востока и Запада посвящено большое количество исследований. Их сближение рассматривается как желанная цель многими философами, культурологами, социологами и политиками. Как интеллектуалы, так и обычные люди тянутся к духовному опыту Востока в надежде расширить горизонты собственного видения мира.

Однако в настоящее время всё громче звучат голоса тех, кто высказывает сомнение в перспективах полноценного диалога Востока и Запада, а также в возможностях понимания восточной духовности западным человеком. 
Например, Э. Гуссерль полагает, что духовному облику Европы имманентна философская идея, и суть европейского духа - разум, свобода и устремлённость в бесконечность. На Востоке же преобладают мистические спекуляции и мифологическая установка. Следовательно, как отмечает философ, выход из духовного кризиса невозможен через ассимиляцию ценностей Востока, т. к. «корни европейского кризиса - в сбившемся с пути рационализме» [1, с. 317].

К.-Г. Юнг, глубоко понимавший принципы восточной культуры, даёт следующую характеристику стремлению западного человека подражать Востоку: «Западу самой судьбой было предопределено познакомиться со своеобразием восточного духовного склада... Перенимая же такие предметы непосредственно у Востока, мы тем самым лишь сдаём позиции нашему западному стремлению к приобретательству, согласно которому всё благое приходит извне» [2, с. 105].

В данной статье мы ставим перед собой задачу показать, что возможность взаимопонимания восточной и западной культур вырастает на почве их обоюдной зрелости. Развитие, как человека, так и культуры предполагает отказ от односторонности и переход к более универсальной точке зрения. Это делает возможным понимание иной личности и чужой культуры. На примере развития философских идей мы рассмотрим некоторые аспекты «взросления» и взаимного сближения восточной и западной культур.

Между мировоззренческими системами Востока и Запада пролегает пропасть, поэтому мы должны постоянно помнить о высокой степени условности любых аналогий, выстраиваемых при сопоставлении этих систем.

В отношении восточной культуры давно укоренился стереотип, согласно которому она, достигнув высокой степени духовности, за счет совершенствуемой тысячелетиями практики интроспекции, чужда научному и философскому видению мира. Наука и технологии заимствованы Востоком у более развитого в этом отношении Запада. Достижения европейской философской и научной мысли общеизвестны и не нуждаются в представлении. Эти достижения - во многом плод разработки и применения методологического инструментария и принципов особого (теоретического) мировоззрения, сформировавшихся на начальных этапах развития европейской цивилизации. Подобная точка зрения отчасти оправдана, однако даёт несколько упрощённую картину диалога Востока и Запада как процесса грубого заимствования чужих преимуществ. Более того, восточная культура часто приводится идеологами возвращения к «естественному» образу жизни через отказ от рационализма, сциентизма и технократизма Запада как пример гармоничного сосуществования с природой. Если исток кризиса Европы - в господстве рационалистического образа мыслей, то обращение к Востоку как носителю иррационального мистического знания рассматривается как панацея от всех бед. Поборники такого подхода зачастую даже не проводят грани между рационализмом как философской концепцией и рациональным мышлением как ментальной способностью, усугубляя непонимание сути вопроса.

В реальности любая великая культура в период зрелости приходит к реализации возможностей, противоположных её изначальным основаниям и смыслам. Нам представляется, что это в полной мере относится к цивилизациям Востока и Запада. Следовательно, появляются точки соприкосновения там, где первоначально демонстрировались принципиально противоположные интенции. Рассмотрим некоторые из них.

Как уже отмечалось, сильная сторона западного мышления - научная методология, в том числе, диалектика. Использование диалектического метода дало огромные преимущества европейской философии и науке. Но появление диалектики стало и проклятием Запада, как полагали многие критики европейской современности, начиная с Фр. Ницше, который рассматривал диалектику как изобретение дьявольского сократического ума, в конечном итоге ставшее причиной гибели европейского духа.

Но является ли диалектика исключительной принадлежностью западного способа мышления, ведь её появление обычно связывают с именами Сократа и Платона? Существовала ли на Востоке традиция рационального мышления, включающая в себя постановку логических и методологических проблем?

Для начала обратимся к историческим фактам. Ранним религиозным школам Востока философские искания не были свойственны. Интерес к логике и диалектике возник не сразу. Тем не менее, в определенный исторический момент такой интерес появляется. Например, Ф. И. Щербатской отмечает, что изучение курса логики в школах при тибетских монастырях продолжалось 
четыре года, и существовало большое количество учебников логики, написанных специально для этих школ [3, с. 110].

Во времена третьего «поворота Колеса Закона» (середина I тыс. н. э.), как именуют этот период буддисты, в различных странах Юго-Восточной Азии были созданы литературные памятники, посвященные проблемам логики и диалектики. Трактаты Нагарджуны об искусстве ведения диспута, семь трактатов по логике Дхармакирти, на которые было написано множество комментариев и т. д.

Сохранились многочисленные источники, свидетельствующие о том, что восточные мудрецы в совершенстве владели искусством аргументации и философского дискурса. Наличие в восточной мыслительной традиции интереса к нормам и принципам рационального мышления достаточно очевидно.

Однако более значимая проблема лежит в иной плоскости: насколько логика и диалектика, существовавшие на Востоке, соответствуют тем требованиям, которые предъявляет к научному инструментарию Запад? Чем отличаются восточный и западный типы рациональности?

Востоку были известны все основные разделы традиционной логики: учение о силлогизме, теория логического вывода, принципы доказательства и опровержения. Хотя имелись и некоторые существенные отличия. В частности, в индийской логике базовым считался пятичленный силлогизм, что связано с его индуктивно-дедуктивной природой (в понимании древних индийцев), а не чисто дедуктивной (как в логике Аристотеля). Также по правилам ведения диспута участники имели право приступать к опровержению точки зрения оппонента без прояснения собственной позиции по предмету спора. Эти различия - в большей степени детали, нас же интересует метафизические основания восточного и западного типов рациональности.

На несходство этих оснований одним из первых обратил внимание Ф. И. Щербатской, отмечавший, что интерес к проблемам логики имел на Востоке изначально философский, а не формальный характер. Индийская логика, например, включала в себя не только учение об истине и заблуждении, условиях достоверности знания, но и теорию восприятия, проблемы адекватности процесса мышления действительности и реальности внешнего мира и т. д.

Логика Аристотеля была оторвана от метафизики, тем более, этики и психологии, имела в большей степени формальный и инструментальный характер. В рамках формальной логики не тематизируется познающий субъект, точнее, проблема субъекта познания становится проблемой элиминации субъективных факторов, влияющих на процесс постижения истины. Эта особенность определила многие тренды в развития европейской философии и науки на столетия. Западная гносеология традиционно уделяет огромное внимание вопросу достоверности источников знания и разработке правильного методологического инструментария. Отметим также, что существование дихотомии «субъект-объект» не подвергается сомнению в рамках классической европейской науки, чего нельзя сказать о восточной интеллектуальной традиции.

В древней Индии, где вся философская проблематика определялась сотериологическими задачами, на первый план выходит проблема реальности Эго-сознания. Неудивительно, что знаменитый логик Дхармакирти является автором трактата «Обоснование чужой одушевленности», в котором, используя метод аналогии, он делает вывод, что субстратом наших представлений об иных душах являются реальные сущности [4, с. 46-47].

Метод рассуждений Дхармакирти в чём-то близок методу «аналогизирующей апперцепции» Э. Гуссерля, согласно которому наличие в моём сознании иных психофизических структур в качестве интенциональных объектов доказывает реальность других «Я», трансцендентных моему собственному Эго. Данный пример свидетельствует, что на Востоке логика включала в себя широкий спектр метафизических проблем, и это обстоятельство связано с отличным от западного пониманием сознания и человека. Вообще достижение спасения возможно через изменение психологических и гносеологических установок, следовательно, изучение логики имеет целью не только развитие мышления, но и нравственное совершенствование, а также «успокоение дхарм» избавление от страдания.

Сложно однозначно ответить на вопрос, почему Востоку изначально была свойственна нацеленность на понимание ментальных процессов из них самих, как бы «изнутри», поскольку чисто феноменологически картина этих процессов содержит в себе различные альтернативы рас- 
смотрения. Возможно, прав был К.-Г. Юнг, который объяснял этот факт глубоко укоренённой интровертивной установкой, свойственной восточной культуре [5, с. 8-11].

$\mathrm{C}$ другой стороны, восточная и западная теории познания имеют много общего. Например, одной из задач буддийской логики было объяснить, каким образом многообразие эмпирически данных предметов может быть познано с помощью единообразных статичных понятий. Известно, что диалектика Платона возникла как метод осмысления проблемы парадоксального соотношения единого и многого, поставленной элеатами.

Итак, мы видим, что Восток в период духовной зрелости порождает развитые философские системы, не уступающие по степени сложности античным образцам.

Скажем ещё несколько слов о диалектике.

Зачастую утонченную диалектику Запада противопоставляют недиалектичности восточного мировоззрения. Для этого есть некоторые основания, однако, на наш взгляд, Востоку тоже нельзя отказывать в способности мыслить диалектически.

Диалектика основана на принципе взаимосвязи и относительности противоположностей. Учениям раннего периода свойственно абсолютизировать различия между противоположностями. Например, для миросозерцания хинаяны характерно двоемирие: абсолют не имманентен миру, сансара и нирвана - разные сферы бытия, физический и нравственный миры подчиняются каузальным законам. В махаяне законы причинности заменяются принципом относительности, идея двоемирия - монизмом, и, как следствие, появляется тема иллюзорности феноменального мира. В позднем буддизме сансара и нирвана относительны, это суть единая реальность, но с разных точек зрения. Вселенная трансцендентна и феноменальна одновременно.

Для более глубокого понимания этого факта обратим внимание на следующее обстоятельство. Ф. И. Щербатской указывал на неправильность общепринятого перевода термина «щуньята». Шуньята - это не «пустота», а «относительность». Шуньята - синонимом процессуального и зависимого бытия [6, с. 26]. Следовательно, всё наше знание имеет относительный характер и есть выявление сути вещей через анализ их взаимосвязей с другими вещами.

Таким образом, Восток демонстрирует искусство мышления, не уступающее в своей утонченности лучшим западным образцам. На смену сотериологическим религиозным концепциям приходит философское мировоззрение.

В свою очередь, Запад, уверовавший во всемогущество безличной методологии познания, в ходе своего развития постепенно пришёл к пониманию ключевой роли человека как субъекта научной, философской и иных форм деятельности. Поворот в сторону антропологической проблематики и постановка вопроса о природе сознания стали возможны после И. Канта. Это произошло ещё до того, как в Европе возник интерес к Востоку и формам его духовной жизни.

Общеизвестно, что критическая теория Канта была попыткой выйти из гносеологического тупика, в котором оказалась новоевропейская философия: наивный реализм Фр. Бэкона и Дж. Локка с одной стороны, солипсизм Дж. Беркли и Д. Юма - с другой. Кант через обоснование активной роли субъекта в процессе познания и благодаря критической философской установке, выразившейся в отказе от абсолютизации познавательной деятельности, открыл для европейской науки и метафизики новые горизонты развития. В частности, благодаря Канту стало возможным создание философской теории ценности. Не философский анализ отдельных ценностейпрекрасного, справедливого, священного, а сущности ценностного отношения как такового. В целом современные концепции сознания берут своё начало в кантовской философии.

Учение Канта имеет определённые параллели с буддизмом махаяны. Теория «вещи в себе», ноуменального и феноменального миров, осознание границ опыта - всё это перекликается с буддийским представлением о природе дхарм и истоках «омрачённости» сознания.

Однако необходимо подчеркнуть, что аналогии между кантианским мировоззрением и доктриной махаяны весьма условны, так как Кант - классический рационалист. В буддийской теории познания ключевая роль принадлежит интуиции и мистическому опыту. В европейской философии интерес к интуиции возник уже после Канта.

В философии Канта не уделяется внимание проблеме бытия иного сознания, следовательно, отсутствует тема диалога различных сознаний, интерсубъективности. Эта тема стала одной из центральных только в философии XX века, например, в феноменологии Э. Гуссерля: «Кто мы суть как субъекты, осуществляющие смысловое... свершение универсальной конституции, кон- 
ституирующие в общности друг с другом мир как полюсную систему, т. е. как интенциональное образование нашей обобществленной жизни?» [7, с. 245]. Человек живёт не в мире природы или богов, а в мире других человеческих субъектов. Ими задаются смыслы, цели и содержание нашей жизни. Непосредственная феноменальная данность для субъекта - это лишь его собственное сознание. Как возможен диалог различных сознаний? Пример трансцендентальной феноменологии Гуссерля демонстрирует, что теория, которая ставит сознание в центр мира, приходит к необходимости философского обоснования интерсубъективных актов. То, что на Востоке было предметом размышлений в течение тысячелетий, стало актуальным и для западной мысли.

Сравнивая восточную и западную культуры, невозможно обойти вопросы, связанные с пониманием человеческой психики и учением о душе. Здесь коренится, наверное, самое существенное различие между Востоком и Западом. Мудрецы Востока, в большинстве своём, считали человеческую индивидуальность иллюзией, а привязанность к ней - источником страдания. Личность существует лишь эмпирически, это не конечная реальность («Анатман»-учение, отрицающее наличие «Я», своеобразная «психология без души»).

Человек Запада не в состоянии представить психику без «Я», поэтому вряд ли он способен адекватно ассимилировать духовный опыт Востока. На это указывали те, кому удалось глубоко понять суть восточной духовности. В частности, К.-Г. Юнг писал в работе «Йога и Запад», что на Востоке, в силу наличия многотысячелетней духовной традиции, йога является великолепным методом единения тела и духа. Но западный человек, в силу имманентно присущего ему конфликта разума и веры, будет склонен воспринимать йогу либо как религиозную доктрину, либо как гимнастику для тела [8, с. 39].

Восточная культура уделяет огромное внимание духовной стороне жизни, концентрируясь на бессознательных и сверхсознательных аспектах психического процесса. Различные философские и религиозные школы Востока не имеют единой точки зрения по вопросу существования человеческой души, и, соответственно, возможности личного бессмертия. Например, некоторые представителя брахманизма допускали наличие истинного индивидуального «Я», но в буддизме особенно в буддизме хинаяны - в отношении человеческого «Я» господствуют нигилистические умонастроения. Следовательно, принцип любви как высшей формы отношения к другому заменяется принципом сострадания, а ценность свободы и личной ответственности - законом причинности. О. О. Розенберг охарактеризовал это состояние духа следующим образом: «По учению буддизма, волнение безначально, оно, следовательно, не есть результат грехопадения, оно не грех, который нужно искупить, а первобытное страдание, которое должно быть приостановлено» [9, с. 191].

С другой стороны, Восток, применяя метод интроспекции, достиг такой тонкости и глубины понимания бессознательной и сверхсознательной психики, которые долго оставались недоступны человеку Запада. Современный Запад в своих духовных поисках активно использует интеллектуальный багаж, накопленный восточными практиками и доктринами. Результаты клинических исследований, открытия этнографов и антропологов предоставили множество свидетельств неадекватности новоевропейского понимания человека. В современной науке и философии Запада появляются многочисленные учения, стремящиеся объединить мудрость Востока и научные достижения Запада. Имена К.-Г. Юнга, С. Грофа, К. Уилбера не нуждаются в представлении. Границы их концептуального понимания человека и его места в мире простираются намного дальше того, что мог вообразить европейский ум ещё два столетия назад.

Заслуживает внимания, например, следующий факт. В гуманистической психологии А. Маслоу, основанной на традиционной западной антропологической концепции, высшей ступенью самоактуализации личности является состояние, соответствующее уровню кентавра [10, c. 123-147] в общем контексте спектра сознания, описанном К. Уилбером [11, с. 100-105]. Это продвинутый, но далеко не высший уровень реализации самости. Следующие уровни сознания, согласно теории Уилбера, основаны на сверхфизической реальности и практически неизвестны в западной психологии. Это тонкие и предельные области психики - Самбхогакайя и Дхармакайя, в терминах буддизма махаяны, - предполагающие трансценденцию Эго-сознания, феноменального мира и границ пространства и времени [11, с. 106-129].

Теории К. Уилбера и С. Грофа показывают, насколько может быть плодотворным диалог восточной духовности и западного интеллектуализма. 
Подведём некоторые итоги. Мы видим, что на Западе интерес к Востоку формировался постепенно. Переводились и изучались философские тексты и литературные памятники, в попытках постичь внутреннюю логику метафизических построений восточной культуры Европа всё в большей степени проникалась её духом и её мировоззрением. Возникали точки соприкосновения и открывались возможности для диалога. Интеллектуальные проблемы, традиционные для Востока, завоёвывали умы европейцев. Однако сейчас уже очевидно, что Запад, оставаясь верным собственной судьбе, должен развиваться на имманентных ему духовных и интеллектуальных основаниях. По выражению К.-Г. Юнга, «мы можем усвоить дух Востока, лишь твёрдо стоя на собственной почве» $[12$, с. 211].

\section{Список литературы}

1. Гуссерль, Э. Кризис европейского человечества и философия // Культурология. ХХ век : антология / ред. С. Я. Левит. - Москва : Юрист, 1995. - С. 297-330.

2. Юнг, К.-Г. Психологический комментарий к «Тибетской книге Великого освобождения» // О психологии восточных религий и философий. - Москва : Медиум, 1994. - С. 91-48.

3. Щербатской, Ф. И. Буддийская логика. Введение // Избранные труды по буддизму. - Москва : Наука, 1988. - С. 54-107.

4. Дхармакирти. Обоснование чужой одушевленности. - Петербург : Ясный Свет, 1922. -79 с.

5. К психологии восточной медитации // О психологии восточных религий и философий / К.-Г. Юнг, сост. В. Бакусев. - Москва : Медиум, 1994. - С. 8-32.

6. Семичов, Б. В. Академик Фёдор Ипполитович Щербатской /Б. В. Семичов, А. Н. Зелинский // Избранные труды по буддизму / Ф. И. Щербатской. - Москва : Наука, 1988. - С. 15-41.

7. Гуссерль, Э. Кризис европейских наук и трансцендентальная феноменология. - Санкт-Петербург, 2004 : Фонд Университет : Владимир Даль. - 399 с.

8. Йога и Запад // О психологии восточных религий и философий / К.-Г. Юнг, сост. В. Бакусев. Москва : Медиум, 1994. - С. 22-46.

9. Розенберг, О. О. Труды по буддизму. - Москва : ГРВЛ «Наука», 1991. - 295 с.

10. Маслоу, А. Мотивация и личность. - Москва : Питер, 2013. - 351 с. - (Мастера психологии).

11. Уилбер, К. Проект Атман: Трансперсональный взгляд на человеческое развитие. - Москва : ООО «Изд-во АСТ», 2004. - 314 с.

12. Комментарий к «Тайне Золотого Цветка»// О психологии восточных религий и философий / К.-Г. Юнг, сост. В. Бакусев. - Москва : Медиум, 1994. - С. 149-222.

Marina A. Nosochenko, $\mathrm{Ph}$. D. in Cultural Studies, Associate Professor, Altai State Institute of Culture (Barnaul, Russia) caperucita.amarilla2016@gmail.com

\section{THE EAST AND THE WEST: PROBLEMS OF INTERCULTURAL DIALOGUE}

Abstract. The article highlights complex and long history of relationships between Western and Eastern cultures. The author considers some peculiarities of development of the Eastern and the Western intellectual traditions in fields of logic, dialectics, epistemology, and theory of consciousness. Comparative analysis of principles of Eastern (Dharmakirti and Nagarjuna's writings) and Western (a case of Aristotle's works) logic and doctrines of a man's soul and ego-consciousness is given. The goal of the paper is to show that true intercultural dialogue can be ground on a search of meeting points in intellectual, artistic, and religious spheres avoiding direct adoptions of alien axiological systems. Such dialogue is possible if cultures reach a high degree of matureness that shown in particular in awareness of limitation of their own metaphysical grounds by cultures themselves. The author concludes: the East initially has an introvertive mental set, while The West has an extravertive one; that gives good opportunities for meaningful dialogue between dissimilar cultures without risking of losing their own identities.

Key words: philosophy, psychology, theory of culture, logic, dialectics, phenomenology, epistemology, theory of consciousness, the West, the East, dialogue of cultures. 